\title{
Effects of Rice Husk Ash and Lime on Clay Soil Stabilization
}

\author{
Kannan DV*, Sahira Banu and A Jahana Jasmine \\ Department of civil engineering, National college of engineering, India
}

*Corresponding author: Kannan DV, Department of civil engineering, National college of engineering, Tirunelveli, Tamilnadu state, India

\begin{abstract}
Expensive soils are fertile and very good for agriculture, sericulture and aquaculture. Though they are good for these purposes they are not suitable for laying roads. On such soil suitable construction practices and sophisticated methods of design are to be adopted. In this experimental work the soil was first stabilized with lime in the proportion of 5\% and $15 \%$, 25\%. Sieve analysis, specific gravity test. Atterberg limits, compaction test and soaked California bearing ratio (CBR) test were carried out. The optimum proportion of lime was found to be $10 \%$ from the CBR results. In the second phase of the work rice husk ash was added in the proportion of 5\%,15\%,25\% in addition with lime. The optimum proportion of lime and rice husk ash was found out from the test results. The addition of lime and rice husk ash to the tested soils led to an increase of the plasticity index and contributed to an increase in the optimum moisture content and a decrease in the maximum dry density. The moisture-density curves of the stabilized soils have typical flattened from compared to the natural soils.
\end{abstract}

Keywords: Atterberg limit; California Bearing Ratio (CBR); Clay soil; Lime; Optimum moisture content; Rice Husk Ash (RHA); Soil stabilization

\section{Introduction}

In contemporary life, road transportation is an integrated part of functioning of any society. The biggest drawback in India is to provide a complete network of road system with the limited available finance to build a road by conventional methods. Therefore, there is a need to restore to one of the suitable methods of low-cost road construction, followed by a process of stage development of the roads, to meet the growing needs of the modern traffic. In India clay soil cover almost one fifth to one sixth of the total land area. The clay soil covers mostly on the Deccan plateau region majorly found over the states of Andhra Pradesh, Tamil Nadu, Madhya Pradesh, Gujarat and Karnataka. The clay soil also found even at the riverbanks. Normally the clay soil possess low strength and undergo volume change in the presence of moisture, clay soil is a typical expensive soil which losses its strength in the presence of water resulting in swelling of the soli and in absence of water it shows multiple cracks due to shrinkage and this makes very difficult to use clayey soil to use in construction. Indian clay soils are rich in montmorillonate; it is a type of clay mineral. This mineral is responsible for swelling and shrinkage behaviour of the soil. Structures on these soils experience large scale damage due to heavy accompanied by the loss of strength of these soils during rainy season and shrinkage in the moisture content.

This soil shows major volume changes due to change in the moisture content. This causes major damage to property constructed on it. These soils contain minerals such as montmorillonite that are capable of absorbing water. When they absorb water their volume increases. Although mechanical compaction, dewatering and earth reinforcement have been found to improve the strength of the soils, other methods like stabilization using admixtures are more advantageous. The different admixtures available are lime, cement, fly ash, blast furnace slag etc. At present cement stabilization now, a day is not preferable because of the increasing cost of cement and environmental concerns sulphates. Presence of sulphates can increase the swelling behaviour of soil due to the formation of swelling minerals such as ettringite and thaumasite. Soil stabilization is the process of improving the engineering properties 
of soil by mixing some binding agent to soil particles. Stabilization, in broad sense, incorporates the various methods employed for modifying the properties of a soil to improve its engineering performance. Soil stabilization is required where the road alignment passing thorough poor soil sub-grade does not comply with the engineering requirements as per any given standard specification. The requirement of finding the other alternative materials is most promising one. This study focused on the use of the industrial waste materials like fly ash and granulated blast furnace slag (GGBS). Fly ash is a by-product from burning pulverized coal in electric power generating plants. GGBS is obtained from blast furnace slag, a byproduct from the manufacture of iron. Industrial waste materials have little or no production cost. Waste materials utilization is not only the promising solutions for disposal problem, but also saves construction cost. The major purpose is to investigate the potential of using industrial waste materials in the field of geotechnical engineering. Various researches have been done on fly ash and ground granulated of expensive soils. In some experimental investigation they found that lime-lime soil stabilized mixes with and without addition of gypsum or containing partial replacement of lime by fly ash produced high Unconfined Compressive Strength (UCS) and CBR in comparison to plain soil. They also concluded that partial replacement of GGBS with fly ash further increased the UCS.

\section{Materials}

\section{Clay soil}

A soil with high clay in nature, high swelling, low bearing capacity (low CBR value) and weak in wet condition was used for this entire experimental work. The soil particle size is between $0.00-0.002$. And the swelling pressure was from $8 \mathrm{~kg} / \mathrm{m} 2$ to $10 \mathrm{~kg} /$ $\mathrm{m} 2$. The specific gravity of the soil sample is 2.6 .

\section{Lime}

Lime is produced by heating limestone which is more or less pure calcium carbonate. During heating $\mathrm{CO}_{2}$ is driven off and the non-volatile impurities such as oxides of silicon magnesium, aluminium, iron and manganese are left behind in the lime. Lime or quick lime as it is sometimes called is an essentially calcium oxide. Pure calcium-oxide (lime) is a white solid which melt at $2570{ }^{\circ} \mathrm{C}$. When the molten is cooled, it solidifies in cubic crystals, but as ordinarily prepared it is non-crystalline and easily powered. For

Table 1: Sieve analysis of soil sample. this study, commercially available lime is used with $60-70 \% \mathrm{CaO}$ content and the specific gravity is 2.12 .

\section{Rice husk ash (RHA)}

Rice milling generates a by-product know as husk. This surrounds the paddy grain. During milling of paddy about $78 \%$ of weight is received as rice, broken rice and bran. Rest $22 \%$ of the weight of paddy is received as husk. This husk is used as fuel in the rice mills to generate steam for the boiling process. This husk contains about $75 \%$ organic volatile matter and the remaining $25 \%$ of the weight of this husk is converted into ash during the firing process, known as Rice husk (RHA). This RHA in turn contains around 85\%-90\% amorphous silica. So far, every $1000 \mathrm{~kg}$ of paddy milled, about $220 \mathrm{~kg}(22 \%)$ of husk is produced, and when this husk is burnt in the boilers, about $55 \mathrm{Kg}(25 \%)$ of RHA is generated [16]. India is a major rice producing country and the husk generated during milling is mostly used as a fuel in the boilers for processing paddy, producing energy through direct combustion and or by gasification. About 20 million tons of RHA is produced annually. This RHA is great environmental threat causing damage to the land and the surrounding area in which it is dumped. Lots of ways are being thoughts for disposing it by making commercial use of RHA. For this study RHA is obtained from the modern rice mill, and it is having $67.8 \% \mathrm{SiO}_{2}$ content. And the specific gravity of the RHA is 2.04 .

\section{Methods}

In order to investigate the structural properties/soil stabilization of blended clay soil, sieve analysis, specific gravity, atterberg limits (Shrinkage limit, plastic limit and liquid limit), standard proctor compaction test and soaked CBR test were conducted as per BIS standards.

\section{Results and Discussion}

\section{Sieve analysis}

The sieve analysis test is carried out in clay soil to ascertain the presence of clay content. The test results are shown in Table 1 From the table, it can be noted that the coarse soil particle is about $36.35 \%$, medium soil particle is $33.3 \%$, fine soil particle is $3.5 \%$ and very fine soil (clay) particle is $20.29 \%$. As per BIS classification (A-line chart) the soil sample is under the category of CL-Clay of high plasticity.

\begin{tabular}{|c|c|c|c|c|}
\hline IS sieve Designation & Mass retained in (g) & $\begin{array}{c}\text { Cumulative Mass retained } \\
\text { Wa (g) }\end{array}$ & $\begin{array}{c}\text { Soil retained as \% of } \\
\text { partial soil Ni=(Wa/ } \\
\text { W1)*100 }\end{array}$ & $\begin{array}{c}\text { Soil passing as \% of soil } \\
\mathbf{N}=\mathbf{1 0 0}-\mathbf{N i}\end{array}$ \\
\hline $4.75 \mathrm{~mm}$ & 2.3 & 1.15 & 1.15 & $98.85 \%$ \\
\hline $2.36 \mathrm{~mm}$ & 7.5 & 38.65 & 37.5 & $61.35 \%$ \\
\hline $600 \mu$ & 33.6 & 55.45 & 16.8 & $44.55 \%$ \\
\hline $425 \mu$ & 8.4 & 59.65 & 4.2 & $40.35 \%$ \\
\hline $300 \mu$ & 8.8 & 64.05 & 4.4 & $35.95 \%$ \\
\hline Pan & 109.4 & 100 & 20.95 & 0 \\
\hline
\end{tabular}




\section{Atterberg limits}

Atterberg limits are the group of tests and it is consisting of shrinkage limit, plastic limit and liquid limit. These tests are conducted to measure the water requirements in a soil for achieving fully compaction state and bearing capacity of the soil. In this work, liquid limit and plastic limit tests were carried out for various combinations of lime and RHA with clay soil. The tests results for lime (L) blended clay soil (CS) and Lime+RHA blended clay soil are presented in the (Figures 1 \& 2). From the Figure 1, when the lime is replaced with clay soil the liquid limit and plastic limits are gradually decreased. It may be due to the fact of the water absorption property of clay higher than the lime. Whereas the

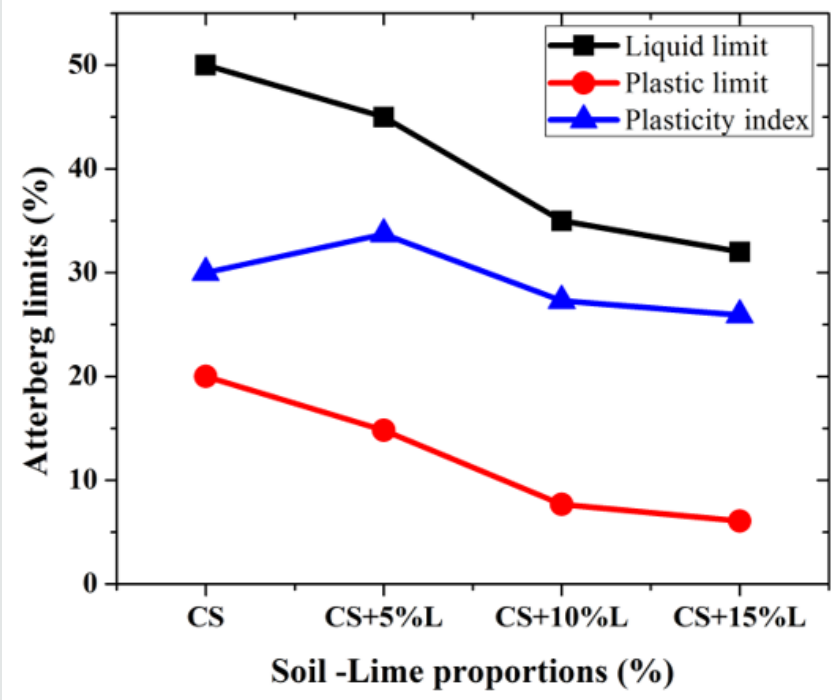

Figure 1: Liquid limit, plastic limit and plasticity index of lime blended clay soil.

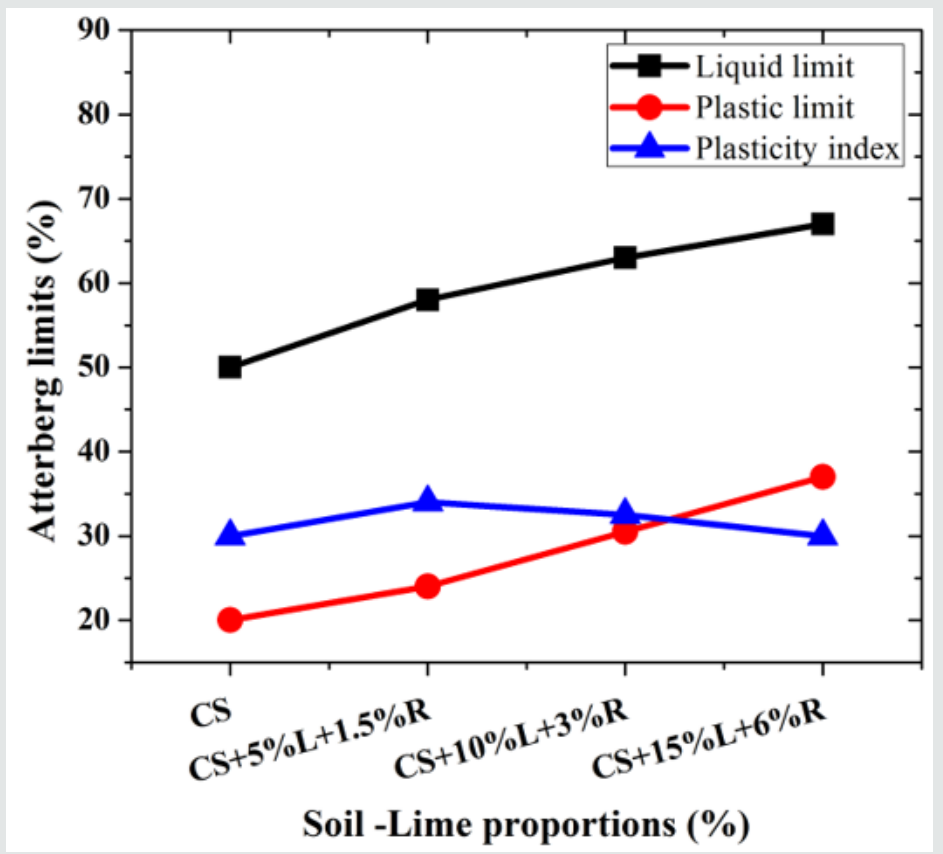

Figure 2: Liquid limit, plastic limit and plasticity index of lime and RHA blended clay soil.

lime and RHA blended clay soils are showing Figure 2 a different trend in the liquid and plastic limit values. When replacing the combination of lime and RHA to the clay soil, the liquid and plastic limit are gradually increasing, it may be due to the fact of RHA and lime are reacting with each other and additional water is needed for the reaction.

\section{Optimum moisture content and dry density}

Standard proctor compaction test is carried out to determine the optimum moisture content (in \%) and dry density of the blended soil. The test results are shown in Figures $3 \& 4$ (for lime blended clay soil) and 4 (for lime and RHA blended clay soil). From the results, the optimum moisture content is increases in lime and 
lime + RHA blended clay soil. Obviously, the dry density of the lime and RHA blended clay soil is decreased with increasing the replacement level. These results are confirming the requirement of high-water content for reaction purpose while adding lime and RHA to the clay soil.

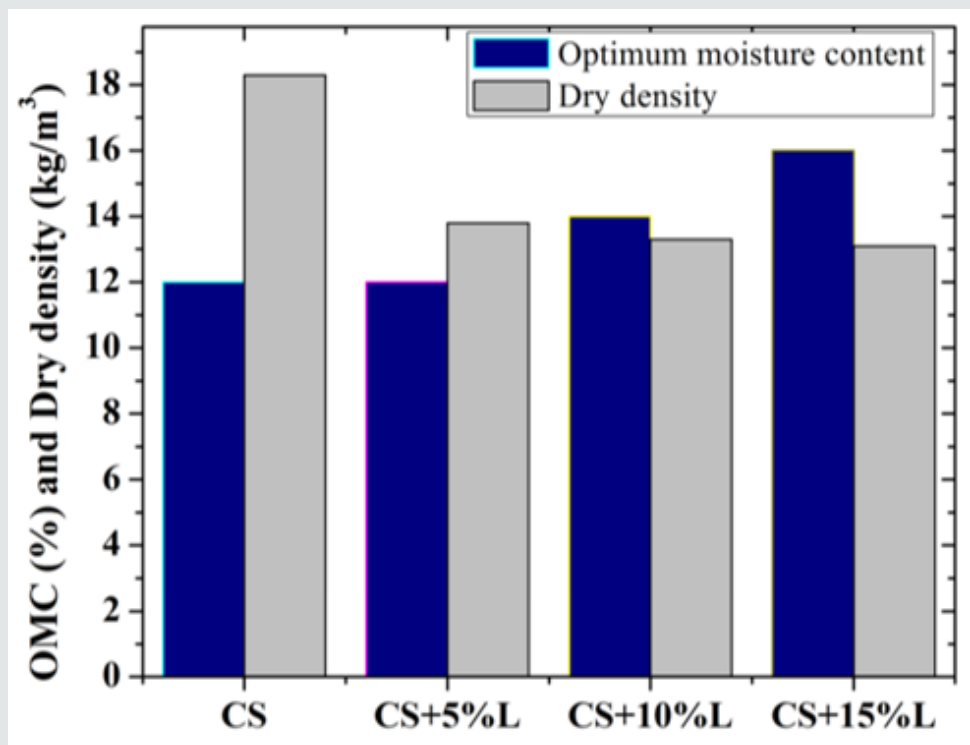

Soil -Lime proportions (\%)

Figure 3: Optimum moisture content and dry density of lime blended clay soil.

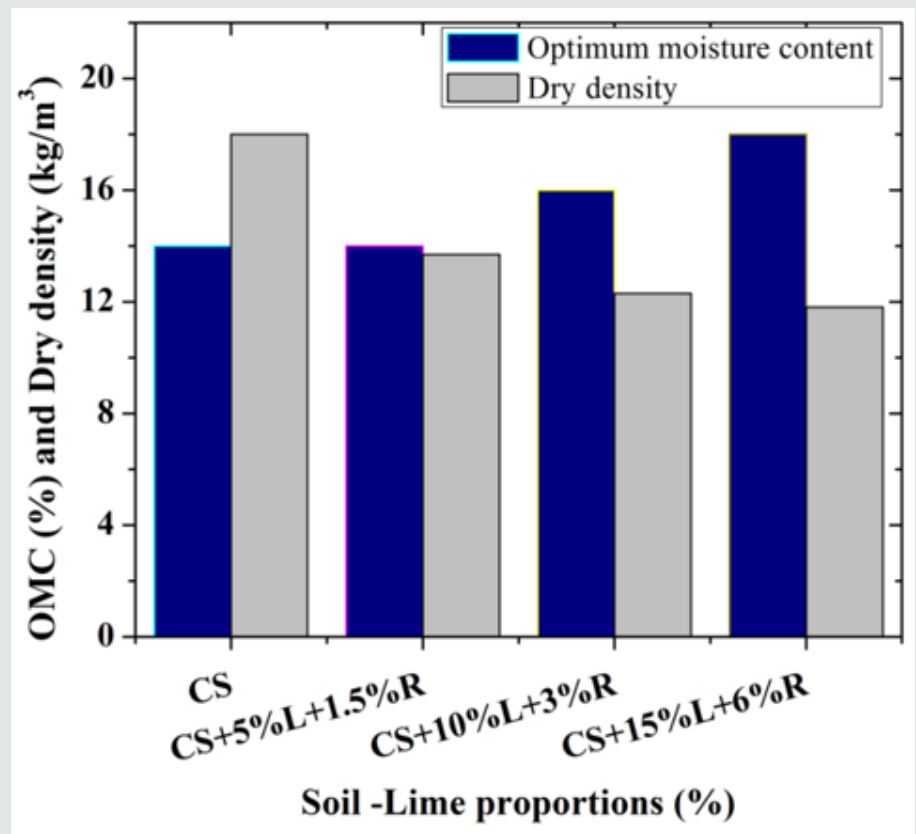

Figure 4: Optimum moisture content and dry density of lime and RHA blended clay soil.

\section{California bearing ratio $(\mathrm{CBR})$ test}

The Figure 5 showing the test results of CBR test for lime and lime + RHA blended clay soil. It is the penetration test evolved for the empirical method of flexible pavement design. Foe expensive soils, the pavement thickness should be based on CBR values of the soil. The soaked CBR value increases on constant addition of lime content and the optimum lime proportion was found out to be $10 \%$. The soaked CBR results are the criteria for determining the pavement thickness for expensive soils. A proportion of $5 \%$ lime and 3\% Rice Husk Ash is found to be optimum for pavement design. From the above result it is concluded that 105 addition of lime to that of the expensive soil showed best results with the increased CBR value of $28.50 \%$. Addition of lime alone with soil often does not increase the strength of soil lime. So, some additives are tried. Pozzolonic materials like rice husk ash and surkhi are the most promising materials in the respect. Lime-rice husk ash stabilization is cheap and is a method with considerable scope for the construction of low-cost roads and where rice husk is available as a waste product [7-13]. 


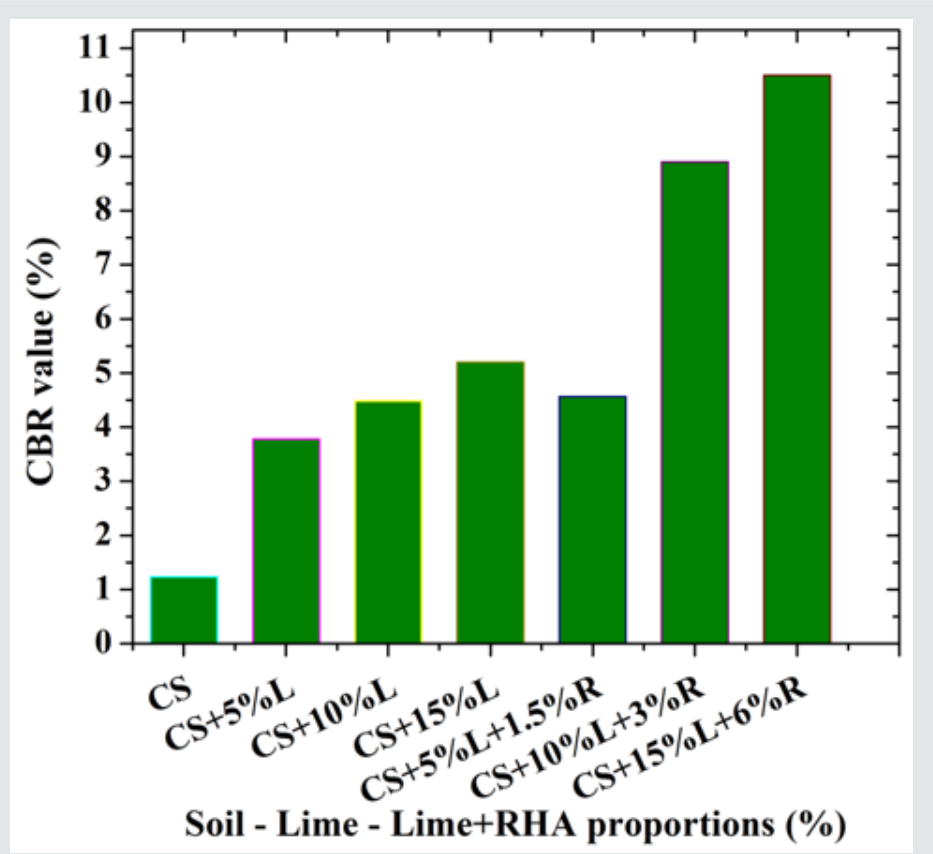

Figure 5: CBR values for lime and RHA blended clay soil.

\section{Conclusion}

From the experimental works the following conclusion may be drawn;

a. The characteristics of a highly expensive soil can be improved by lime, rice husk ash stabilization.

b. Lime and RHA increase the liquid limits while the plastic limits decreased. As a result, the plasticity indices increased. Swelling potential of expensive soil diminished with the addition of admixtures.

c. In lime stabilization, higher lime content is needed for improving the California Bearing Ratio (CBR) of the soil, addition of stabilizers i.e., Rice husk ash not only increases the CBR of the soil but also replaces the quantity of lime to great extent.

d. Addition of Rice husk ash with lime reduces the cost for provision of flexible pavement.

e. If lime- Rice husk ash stabilization is used instead of lime stabilization, for expensive soils, a percentage of 25 to 50 can be saved per load.

f. The study has been successfully conducted to assess the geotechnical properties of expensive soils improved with RHA and lime. RHA and lime altered the texture of expensive soil by reducing the fine particles.

g. While in lime stabilization higher lime content is needed for improving the California Bearing Ratio (CBR) of the soil, addition of one more stabilizer i.e., Rice husk ash not only increases the CBR of the soil but also replaces the quantity of lime to great extent. h. The improvement of the sub-base \& sub grade of the soil having optimum dry density of $1.65 \mathrm{~g} / \mathrm{cc}$. when lime $10 \%$ but it little least as 1.50 when the lime \&rice husk ash of $3 \%$ in this expensive soil.

\section{References}

1. Choudhary AK, Gill KS, Jha JK (2012) Improvement in CBR Values of ExpansiveSoil Sub Grades Using Geosynthetics. p. 233.

2. IRC 37-2001: Guidelines for design of flexible pavement.

3. Jhaand JN and Gill KS (2006) Effect of rice husk ash on lime stabilization. Journal of the Institution of Engineers 87(27): 33-39.

4. Khanna SK, Justo EG (2001) Highway engineering new chand \&bros, roorkee (u.a). ( $8^{\text {th }}$ edn).

5. Pardeep Singh, KS Gill (2012) CBR Improvement in Clays Soil With GeoGrid Reinforcement. 2(6): 2250-2459.

6. Patrick KhaoyaBarasa, Too Kiptanui Jonah, SM Mulei (2015) Stabilization of Expensive clay using lime and sugarcane bagasse ash. 4(4).

7. Punmia BC (2005) soil mechanics and foundation engineering. $\left(16^{\text {th }}\right.$ edn) Laxmi publication.

8. Raju GVRP, Chandrasekar BP, Kumar RRP, Mariyanna G Strength characteristics of Expensive Soils stabilized with lime and rice husk ash. proceeding of Nation.

9. Sathish Chandra, Shiv Kumar, Rajesh Kumar Anand (2005) Soil stabilization with lime and rice husk ash. India Highways, Indian roads Congress 33(5): 87-98.

10. (1998) Seminar on road transportation. Issues \& strategies, Patiala, India, p. 20-29.

11. Singh HP (2012) Improvement in CBR Value of Soil Reinforced With Geotextiles Layers. 5(2): 1438-1442.

12. Vinod Sonthwal, Dheerj Sahni (2015) Subgrade Soil Improvement Using Jute Fibre 1: 237-240.

13. Yashas SR, Muralidhar HR (2015) Improvement of CBR Using Jute Fibre For The Design of Flexible Pavement. 4(9): 870-873. 
CC (P) This work is licensed under Creative

To Submit Your Article Click Here: Submit Article

DOI: $10.32474 /$ MAMS.2019.01.000121

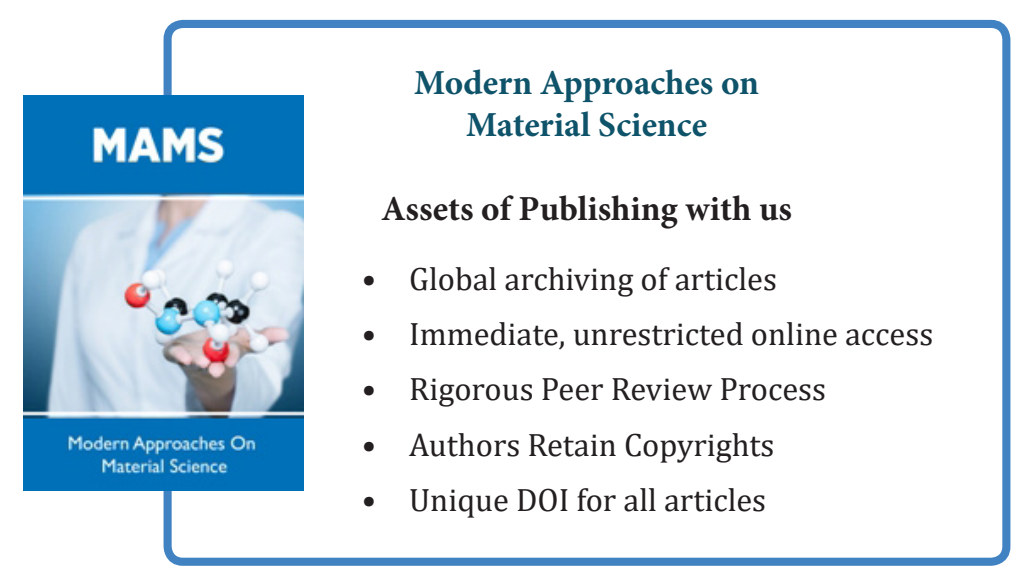

